\title{
DOSSIER
}

\section{MÉXICO: GUERRA FRÍA \\ E HISTORIA POLÍTICA}

$\Psi_{\text {revolución mexicana hasta una historiografía políti- }}^{\text {a iniciado la transición desde una historiografía de la }}$ ca de la posrevolución. ${ }^{1}$ Ésta ofrece perspectivas, conceptos y narrativas para esclarecer el periodo que va de la segunda guerra mundial al agotamiento del autoritarismo clásico, que se puede establecer en algún momento entre la segunda mitad de la década de 1970 y finales de la siguiente. Pero la historiografía de la posrevolución en ciernes no podrá hacer tabla rasa de la Revolución misma: ésta sorteó las grandes calamidades y conmociones del siglo xx, es decir, las salidas fascistas e integristas católicas, el golpe de Estado y la dictadura pretoriana y, quien lo dijera, otra revolución popular. Sin duda, el costo fue alto para la democracia y la justicia

${ }^{1}$ La mayoría de los argumentos aquí esgrimidos viene de un ensayo más amplio; véase Ariel Rodríguez KuRI, "La larga marcha. De la revolución a la posrevolución en México”, en Rogelio Altez y Manuel Chust (eds.), Las revoluciones en el largo siglo XIX latinoamericano, Madrid, Fránckfort del Meno, AHILA, 2015, pp. 237-265. 
social, porque diferentes gobiernos nacionales ejercieron violencia contra sus propios ciudadanos (con más saña si éstos eran campesinos y trabajadores). Sin duda, se extraña todavía en la historiografía un vocabulario preciso y ajustado para denominar la violencia organizada y sistemática ejercida por el gobierno nacional y local (por ejemplo, en la Costa Grande de Guerrero en la primera mitad de la década de 1970) contra ciertos grupos sociales en el periodo 1940-1970.

Los grandes temas de la historia política moderna (a saber, la formación y límites del Estado; la naturaleza de la representación política; la creación y funcionamiento de partidos políticos; la vida pública; la dinámica de las elecciones locales y nacionales; el consenso, el disenso y la violencia; el peso específico del contexto internacional en la política nacional) han aparecido, con suerte desigual, en la historiografía de la posrevolución. En nuestro caso, tres de los textos que aquí se presentan recogen problemáticas asociadas al contexto internacional, a saber, la trayectoria del comunismo mexicano en el marco de la Guerra Fría, las repercusiones políticas para México del golpe de Estado en contra del gobierno de Jacobo Árbenz en Guatemala en 1954, y los intentos por modificar las relaciones entre la Unión Soviética y México al iniciar la década de 1960. El cuarto trabajo se refiere a las respuestas específicas del gobierno mexicano, en términos narrativos y de propaganda, a la crisis suscitada por el movimiento estudiantil de 1968.

En todo caso, quizá resulte útil fijar algunas de las premisas y hallazgos generales de la historiografía política de la segunda posguerra, dado que, en menor o mayor medida, son compartidas por los textos hoy publicados: 
1. La idea e imagen de un "sistema" político, con pocos y previsibles movimientos y quiebres en el tiempo, se ha debilitado en sus alcances explicativos. La preocupación por encontrar claves del sistema político ha sido legítima, dadas las características del régimen en la segunda posguerra mundial: su estabilidad, la hegemonía de un partido casi único, los niveles de crecimiento económico, la identidad de su política exterior. Pero sobrevalorar las virtudes sistémicas del modelo implicó el riesgo de omitir lo que sólo una narrativa histórica, con sus consecuencias gnoseológicas, podía ofrecer: reconocimiento de los protagonismos individuales o colectivos, la política de las incertidumbres y las coyunturas no previstas, la psicología de masas y de los efectos no deseados. ${ }^{2}$ Los cuatro trabajos aquí presentados asumen la incertidumbre como asunto de la historia: las trayectorias inciertas de los comunistas mexicanos; los efectos del golpe de Estado en Guatemala en la política del presidente Adolfo Ruiz Cortines; la peculiar coyuntura internacional y nacional que dio pie a la visita de Mikoyán, ministro de relaciones exteriores de la Unión Soviética, en plena Guerra Fría; y la manera bizarra en que se despliega una campaña de contrainformación del gobierno mexicano luego del 2 de octubre de 1968.

2. Dos polaridades definen los límites de la historia del orden político mexicano a partir de la década de 1940. De un lado tenemos el fenómeno de la estabilización autoritaria de la política y del conflicto, que incluye el fortalecimiento

2 Ariel Rodríguez Kuri, "El presidencialismo en México. Las posibilidades de una historia", en Historia y Política. Ideas, procesos y movimientos sociales, 11: 1 (2004), pp. 131-152; Soledad Loaeza ha hecho una enunciación impecable de este problema, véase Soledad LoAEZA, "Discurso por la discontinuidad en la historia”, Nexos (ene. 2015), versión digital. 
del partido oficial (la mutación del Partido de la Revolución Mexicana en Partido Revolucionario Institucional, un tema crucial en la historia política mexicana), la promulgación de nuevas leyes electorales y la instauración de ciertas normas no escritas que dieron al presidente de la República el papel de árbitro y otorgador de favores, aunque con fortísimas limitaciones en su actuar. ${ }^{3}$

Pero existe otra dimensión, igualmente efectiva y pertinente: la prevalencia de ciertas formas de violencia, que en el periodo dejó de ser el método de las élites para dirimir sus diferencias, pero continuó vigente en la política abajo-arriba, es decir, en la lucha inter e intraclasista. ${ }^{4}$ En otras palabras, existe un consenso historiográfico según el cual el proceso de estabilización política redujo la apelación al recurso de la violencia en las disputas de las élites mexicanas. ${ }^{5} \mathrm{Y}$ la respuesta que se perfila no puede ser muy original: el ejército no dejó de ser el administrador de la violencia por excelencia, la primera y última trinchera en la aplicación de la coerción estatal. ${ }^{6}$ El ejército sería la gran policía nacional y el administrador directo de la protesta, el descontento y la

3 Soledad Loaeza, “La reforma política de Manuel Ávila Camacho”, en Historia Mexicana, LXIII: 1 (249) (jul.-sep. 2013), pp. 251-358.

${ }^{4}$ Alan Knight, "Habitus and Homicide: Political Culture in Revolutionary Mexico", en Wil Pansters (ed.), Citizens of the Pyramid. Essays on Mexican Political Culture, Amsterdam, Thela Publishers, 1997, pp. 107-130; Wil PAnsters, "Zones of State-Making: Violence, Coercion, and Hegemony in Twentieth-Century Mexico", en Wil Pansters, Violence, Coercion and State-Making in Twentieth-Century Mexico. The Other Half of the Centaur, Stanford, Stanford University Press, 2012, pp. 3-39. 5 Alan Knight, "Habitus and Homicide".

6 Thomas Rath, Myths of Demilitarization in Postrevolutionary Mexico, North Carolina, University of North Carolina Press, 2013. 
desobediencia. Éstos serían sobre todo habitantes del mundo rural (un universo fragmentado y disperso en el territorio) pero en su momento también obreros (como en las grandes asonadas del gobierno contra los sindicatos nacionales de industria) y estudiantes serían contenidos o reprimidos por las fuerzas armadas. Pero como muestra el artículo de Pablo Tasso, una vez ejercida la represión contra disidentes, como el 2 de octubre de 1968, se requiere de racionalizaciones y narraciones que den sentido y justifiquen esa violencia. Aquí la violencia en última instancia exige del panfleto y del libelo, de un marketing del orden autoritario.

3. Uno de los grandes mitos del enfoque sistémico ha sido el de la omnipotencia presidencial; ésta encuentra una gran escollera en la posición geopolítica de México. Diría que los miles de kilómetros de frontera con Estados Unidos son, en realidad, un factor endógeno de la política mexicana. Las novedades historiográficas, aquí, se desarrollan en varios planos. Conocemos ya de un virtual acuerdo de libre comercio con Estados Unidos a partir de 1942 y de un tratado migratorio favorable a los trabajadores mexicanos y, sobre todo, de la normalización de las relaciones binacionales al calor de la segunda guerra mundial. ${ }^{7}$ La Guerra Fría abonará en la sobredeterminación de las relaciones con Estados Unidos, señalando al mismo tiempo al presidente unos límites insalvables, pero también alentando o permitiendo ciertas cuotas no desdeñables de autonomía hemisférica del

\footnotetext{
7 Enrique CÁrdenas, "El proceso de industrialización acelerada de México (1929-1982)”, en Enrique Cárdenas, José Antonio Ocampo y Rosmary Throp, Industrialización y Estado en América Latina. La leyenda negra de la posguerra, México, Fondo de Cultura Económica, 2003, pp. 240-276.
} 
Estado mexicano en política exterior y política interna. ${ }^{8}$ No hay mejor ejemplo que el trabajo de Soledad Loaeza en este volumen: el golpe de Estado de 1954 en Guatemala es un asunto muy cercano a la política interna de México y un tema relevante en la relación con Estados Unidos. Y en el trabajo de Vanni Pettinà, la visita del canciller Mikoyán y una exhibición comercial y científica soviética en México resultó en coartada y mensaje para Washington.

4. Ahora bien, ¿cómo se reúne la trayectoria de la historia política mexicana de la segunda posguerra (la del oficialismo y la de los grupos opositores) con el sentido y contenidos de la Guerra Fría? O de otra forma, ¿cómo vivió México la Guerra Fría? En todo caso, parece confirmarse la sospecha de que los alegatos abstractos sobre la soberanía y autodeterminación de los pueblos obedecían también a las necesidades de regular el conflicto interno de las élites, en especial la de los contingentes de los expresidentes Cárdenas y Alemán en la política mexicana. ${ }^{9}$ Como es común en otras experiencias,

8 Soledad Loaeza, "Modernización autoritaria a la sombra de la superpotencia, 1944-1968”, en Nueva Historia General de México, México, El Colegio de México, 2010, pp. 652-694.

${ }^{9}$ Lorenzo Meyer, "La Guerra Fría en el mundo periférico. El caso del régimen autoritario mexicano. La utilidad del anticomunismo discreto", en Daniela Spenser (coord.), Espejos de la Guerra Fría. México, América Central y el Caribe, México, Miguel Ángel Porrúa Editores, Secretaría de Relaciones Exteriores, Centro de Investigaciones y Estudios Superiores en Antropología Social, 2004, pp. 95-117; Jürgen Buchenau, "Por una Guerra Fría más templada: México entre el cambio revolucionario y la reacción estadounidense en Guatemala y Cuba”, en Daniela Spenser (coord.), Espejos de la Guerra Fría. México, América Central y el Caribe, México, Miguel Ángel Porrúa Editores, Secretaría de Relaciones Exteriores, Centro de Investigaciones y Estudios Superiores en Antropología Social, 2004, pp. 119-149; Soledad LoAezA, "Modernización autoritaria”. 
la política exterior es una faceta de la interior. No extraña entonces que la Guerra Fría operara también en otros ámbitos: en la calle y en los ejercicios de propaganda de los gobiernos mexicanos y de la Iglesia católica, desde la promulgación de la Doctrina Truman en 1947 y al menos hasta mediados de la década de $1970 .{ }^{10}$

Pero el anticomunismo oficial u oficioso para desacreditar o reprimir luchas por derechos políticos o ciudadanos resultó menos eficaz en 1968. Cuando iniciaron las protestas estudiantiles en julio, la respuesta más inmediata en la prensa bajo control gubernamental fue exhibir los arrestos de jóvenes como necesarios, dada la responsabilidad de comunistas u otras fuerzas "oscuras". Pero la estrategia se desgastó en las siguientes semanas y es probable que sólo haya regresado en la segunda mitad de septiembre y en los días que siguieron a la represión del 2 de octubre - y regresó acompañado de una virtual ocupación militar de la Ciudad de México-. Tal vez esto ilustre las intuiciones del oficialismo mexicano en la Guerra Fría, es decir, la necesidad de atemperar los discursos anticomunistas y utilizarlos casuística pero no sistemáticamente. Más aún, el artículo de Horacio Crespo muestra que la realidad política de los comunistas mexicanos no era muy halagüeña, aunque sí pertinaz desde 1940. Resulta sintomático que no sólo fueran las políticas de Estados Unidos o del gobierno mexicano las que dificultaban o impedían el desarrollo de un partido de masas, sino los propios intereses soviéticos, complacidos de jugar la carta mexicana en su relación con Washington.

10 Soledad Loaeza, "Modernización autoritaria". 
Más allá, 1968 (o tal vez la década entera) ya es un tema historiográfico. Su programa contempla la necesidad de esclarecer la política internacional del Estado mexicano (Cuba, los Juegos Olímpicos, la protesta estudiantil en lo que ésta tiene de "global", la militancia mexicana a favor de la desnuclearización de América Latina, el coqueteo con el movimiento de los países no alineados) y a partir de ahí inferir la correlación con la política nacional. Pero se puede proceder en sentido contrario: cómo la política local determinó la política internacional. Este último parece ser el guión de la política mexicana en la década de 1970 . Aunque acá la literatura se debilita en número de trabajos propiamente históricos, ya asoman propuestas analíticas e interpretaciones. De todos modos podríamos asumir la misma perplejidad que con el inicio y fin de la Revolución; sabemos que la posrevolución inició a mediados de la década de 1940 pero, ¿cuándo terminó? Es otra historia.

Ariel Rodríguez Kuri El Colegio de México 